This is an Accepted Manuscript of an article published by Taylor \& Francis in Theatre and Performance Design on 25 September 2020, available online:

https://www.tandfonline.com/doi/abs/10.1080/23322551.2020.1771943?journalCode=rdes20

\title{
Scenography 2019 in PQ Talks
}

\section{Barbora Př́íhodová and Pavel Drábek}

The Prague Quadrennial's new Artistic Director, Markéta Fantová, and her team came with a revised model for the 2019 edition of PQ. One of the changes was the promotion of PQ Talks into a full programme in the event. The new concept of PQ Talks also incorporated most of the other "speaking" events- from keynotes, through awards, to roundtables invited from the other programmes. Given the popularity of PQ Talks in previous years, the new concept capitalized on the social joys of dialogue and of the spoken word that complements the visual, spatial, acoustic and haptic experience of scenography and design. It also became an important tool towards political and intercultural plurality and inclusivity in that it offered a chance to participate and present work to scenography practitioners and scholars who would otherwise be unable to become part of the programme. The ability to attend Prague Quadrennial is still greatly dependent on economic, institutional or political privilege, and for that reason, much of what we consider scenography or performance design does not make it to the PQ. "Everyone can be here - if they can afford it" is the underlying dictum of most festivals and events welcoming to the widest possible international public. While that dictum still holds, the new PQ Talks were intended as a significant step towards making active participation in the world's largest exhibition of performance design and scenography possible to a wider range of professionals.

\section{PQ Talks: The Curators' Concept}

PQ Talks 2019 was conceived as an autonomous curated project and a platform to present and discuss the creative, intellectual and cultural riches that scenography brings. In keeping with the Prague Quadrennial 2019's three designated themes, Imagination-Transformation-Memory, the programme published an open call for proposals inviting speakers to address what scenography is, has been, and could be globally and in its broadest possible sense. Our political aspiration towards greater inclusivity envisioned a forum that would offer a chance to voice alternative views, often polemic, and in this way create a plural community that would - temporarily at least, festival-wise - engage in a more inclusive dialogue and offer the microphone to rational and cultivated views on scenographic practice.

PQ Talks 2019 was intended as a space for diverse ideas within the artistic and academic communities, and to understand the different ways scenography is conceived by different artists, within different cultures, and traditions. As curators, we encouraged talks about important scenographers, artefacts, institutions, and events (current or historic). We also welcomed experimental, visionary, and provocative interventions that focused on the unknown and the 
indeterminate, rather than aspects of scenography that are known; exploring not only the image, the artefact and the message, but also the hidden, the possible, the uncertain, the propositional, and the playful.

The response to the open call was overwhelming and that in itself was a first sign that the new concept was viable and welcome. The high quality was another surprising thing - perhaps indicative of the professional public that follows the activities of the PQ. While we were unable to accommodate all of the viable proposals - and certainly not in their often maximalist expectations - we grouped our selection according to theme and significance or disciplinary momentum. We worked with a range of formats - from keynotes and long presentation panels, through roundtables, discussion panels, curated thematic blocks (with individual presenters talking for 15-20 minutes) to a revised format of the Flashtalks: 10-minute presentations on a varied range of projects and ideas, conceived as a kaleidoscopic display of the plurality of practice and diverse (and sometimes quirky) initiatives.

Our thematic arrangement of the proposals offered another opportunity for curatorial intervention. Several of the themes proposed had the potential to become a momentous intercultural dialogue - such as scenography and urban architecture, education, new technologies or collaboration. In such instances we approached scholars, practitioners or experienced presenters to help us organize individual themes and convene these blocks. This offer often came with a request to reach out to cultures that were underrepresented, to practitioners or projects that have not been sufficiently within PQ's scope, and sometimes — to enhance plurality and question dominant discourse. A significant challenge was tackling the dominance of Anglo-American voices. Given the economic and political power of wealthy nations and their institutions - whether from the US, the UK and occasionally Germany - a (un)surprising number of proposals from these countries were in danger of dominating the programme. Our curatorial intent was to mitigate this trend - partiallyattributable to the post-colonial effect of English as the official language of the PQ - by bringing in other cultural discourses, or "other epistemologies" (to use Boaventura de Sousa Santos's term; cf. Santos 2014, particularly Chapters 7 and 8), and requiring that the programme of PQ Talks be truly international and intercultural.

It is worth observing how politics of academic research manifested itself on the programme. Some sending universities would condition their funding to attend PQ by requiring that the presenters gave an "important" talk, as a 10-minute Flashtalk would allegedly not warrant the expense. Many universities (often from the US) require their academics to enhance their presence at the event in other ways, by official titles given to them or by presence in the media and official communiqués. The UK's Research Excellence Framework assesses academic research on the extent and reach of the research impact beyond the academia, which is ranked on a scale internationally recognized, through internationally excellent to world-leading. Other research institutions and think tanks, financed from international and private funds, similarly assess the success of their public engagement and dissemination on the influence they can have on external bodies. Understandably, for several participants PQ Talks — as a forum sitting on the 
borderline between academic research, professional practice, and the wider public (with the programme now available on the Prague Quadrennial's YouTube channel) - were a strategic arena to promote their agendas. Logically, such power discourses at times threatened to compromise the generosity of the discussions and caused obstacles to an inclusive and pluralistic curatorship. (One extreme example was the unwillingness of a transnational organisation to share the stage with an analogous project from another country - allegedly because that would disrupt their agenda.) Another obstacle was the reluctance of some well-established institutions and collaborative groups to open up to dialogue "outside the club". Luckily, these were exceptions rather than the rule but they are an important symptom of the political landscape of academic and artistic practice. They also indicate how detrimental assessment policies can be to issues of equity and inclusivity.

The thematic blocks curated from the call provided a framework for the resulting programme. For some of the blocks we appointed special convenors to help; some of these conveners were recruited from the proposers, others from participants from PQ programmes; in a few cases, we reached beyond the PQ and brought in convenors for specific thematic blocks. There were also themes that we believed to be important in relation either to the work presented in other PQ programmes or recent innovations and trends in the field. In such instances we asked convenors to create their own thematic blocks as appropriate. Many of the organizers ended up moderating the sessions they helped shape - such as the block organized and moderated by Rosane Muniz, on international curatorial practices with Jochen Volz (Pinacoteca de São Paulo), Kate Bailey (V\&A Museum in London and PQ 2019 Jury Member), and Markéta Fantová (PQ's Artistic Director). The following thematic blocks created the structure of the programme, complemented by daily blocks of more-or-less assorted Flashtalks and the other "speaking" events mentioned above:

- Historiographies and Theories;

- Collaborations in Scenography (in part organized by Simona Rybáková).

- International Curatorial Practices (organized by Rosane Muniz).

- Costume (organized by Rachel Hann, Rosane Muniz, and Sofia Pantouvaki).

- Scenography and Politics.

- Pedagogy (in part organized by Daniella Portillo Cisterna).

- Scenography and Sound (organized by Cat Fergusson).

- Scenography Across Arts Forms (in part organized by Anna Wołosz-Sosnowska).

- Scenography and Memory.

- New Media (in part organized by Christopher Baugh).

- Theatre and Photography (organized by Amy Skinner).

- Transforming Scenography (in part organized by Rachel Hann).

- Expanding Scenography.

- Scenography, Urban Space, and Architecture. 
The new-concept PQ Talks included a series of invited speakers giving keynote or other talks. The 2019 edition had three keynotes: opera director and scenographer Stefano Poda; book illustrator, printmaker and former stage designer Olivia Lomenech Gill; and the curatorial and artistic team for the project $36 \mathrm{Q}^{\circ}$ - Blue Hour. Additional guests were welcomed in collaboration with the Goethe-Institut in Prague and the Theater der Zeit publishers for two talks: scenographer Bettina Meyer for one, and scenographer Annette Kurz and her artistic partner director Luk Perceval. In collaboration with the Fragments programme (curated by Klára Zieglerová), PQ Talks also hosted a roundtable discussion of some of the international "legends of scenography" whose work was displayed as part of the Fragments exhibition. That programme hosted daily talks with its exhibiting artists in their dedicated space, independent of our programme. Since we conceived PQ Talks as a platform for encounters and the setting up of links, we also held a panel dedicated to publication platforms including publishers, academic journals and institutions that focus on performance design and scenography. We also gave space for brief self-presentations and invitations to related organisations and institutions - such as the UNIMA (Union internationale de la marionette), whose two exhibitions and a conference celebrated the anniversary of its founding in Prague in 1929, the Tanec Praha Dance Festival, and the IFTR Scenography Group, which hosted a conference parallel with PQ.

The emphasis on the community formed by PQ's participants - whether through presenting or joining in as audiences - helped to create a very open, warm atmosphere in which genuine, thought-provoking dialogue could happen, often spontaneously breaking the divide between the podium and the floor. As organizers and curators, we placed a lot of emphasis on helping those with limited command of English to be heard. We believe this helped our mission to be more diverse and to bring in new perspectives and open the forum to participants from many more cultures than would otherwise feel confident to stand and speak on a podium in a 400-seat hall. PQ Talks received an overwhelmingly positive response from audiences and became a popular venue for surprisingly numerous participants. From the feedback we received, we understood that our audiences were keen to complement their visual and kinetic, and often provocative and unsettling experience of PQ's exhibits with the social aspects of PQ Talks. For them, the dialogue and the conversations taking place in our programme provided a human dimension to the artefacts and arts events and helped their contextualization and understanding.

\section{Selected Case Studies}

The scenography presented at PQ Talks by almost 200 hundred speakers from five continents, manifested itself in multiple forms, whether working with/from a dramatic text or beyond it, whether using a formal theatre space or happening in the streets, whether representing a place, evoking atmosphere, or framing a physical space, in which an action may occur. 
It is beyond the scope of this essay - and also outside our aim - to capture the plurality of ideas, propositions, and projects presented during the full ten days of PQ Talks 2019. An overview of the programme can be found in the PQ Catalogue. Neither do we intend to identify trends or tendencies since we believe that such a perspective would necessarily manipulate the diverse cultural realities that presenters spoke about. While all of the presented projects and scenographic interventions responded to local concerns, very few attempted to make global assumptions or make assertions that would or should be followed elsewhere. In other words, the notion of trend-setting - so prominent in modern Western jargon of managers, influencers, promoters and research assessors - would be an ideological imposition, a manifestation of cultural or epistemic imperialism, against which several presentations explicitly objected.

What ties all these ideas, propositions, and projects together is the Prague Quadrennial as a "domain" that serves multiple "communities of knowledge" (McKinney 2016, 7) centered around scenography and performance design. The fact that PQ participants actually form a strong community, albeit highly changeable, was palpable during the panel discussion "Political Strength of Scenography," initiated and moderated by Rosane Muniz. Scenographers, directors, performers, dramaturges and other cultural workers from Brazil and Catalonia discussed their artistic responses to the crisis of democracies in their countries, in the past and, most acutely, in the present. Raising expressions of solidarity and support throughout the filled space of PQ Talks, the panel demonstrated that scenography cannot be detached from larger political struggles, including censorship and restricted freedom of expression. Shifting from purely aesthetic, stylistic, or technological aspects of scenography, it revealed the affective dimension of the community that the PQ facilitates. This panel highlighted the political agency of scenography most explicitly; however, as the following examples suggest, many of the creative activities presented at PQ Talks once again demonstrated scenographers' ambitions to assume a crucial role in the whole of the performance and beyond, take an active position towards the world around them and make interventions into public space by addressing political, ethical and ecological crises in their communities.

What follows is a critical account of four selected case studies that exemplify diverse creative practices from around the world, many of them actively - or even in an activist way - using scenography as an intervention against globalizing ideological, political or cultural forces.

\section{Example 1: Scenography as a Multiple Translation}

Tamara Figueroa Álvarez, scenic designer and professor of scenography from Chile, considers the work of a scenographer as an act of translation between 'artistic languages'. Her perspective combines 'colonialist and indigenous heritage of South America,' as well as the written and the oral traditions that inform scenography. One of the underlying points of Figueroa Álvarez's contribution was the insistence that the scenographer works with 'landscape' as the 'first frame 
in which a scenic design finds support.' (Figueroa Álvarez 2019) Focusing on landscape makes us reconsider the common assumption of space as one of the core elements of scenography. Additionally, her emphasis on the scenographer who finds 'support' in 'landscape' as its frame, as opposed to the one who sculpts a space to create new physical worlds, recasts the relationship of the scenographer towards the 'material' he/she works with. Further working with 'landscape' as both environmental reality and a metaphor, Figueroa Álvarez claimed that scenographers are involved in an act of multiple translations as they

...travel in landscapes and borders of different times, perceiving and capturing realities to position them in others; [they] weave senses through the hybridization of meanings, because [they] read, [they] translate and [they] stage. The language of stage design, then, is a mestizo language and does not look like anything because it is similar to everything. (Figueroa Álvarez 2019)

Figueroa Álvarez's presentation was part of the thematic block on "Scenography and Memory", and was framed by a performance by Stefany Duarte, ${ }^{1}$ who walked slowly in-between the audience with a large image composed of two photographs: one of them capturing Machi Francisca Lincona, Chile's Mapuche (Indigenous) political and spiritual leader, and the other an image of military suppression of civic protests. When she made it onto the stage, she tore the photographs into small pieces, later offering those fragments to the audiences. Weaving together Duarte's action, carefully choreographed "visual pauses" during which she let the audience silently dwell on projected photographs pointing to the current political climate in Chile (suppression of indigenous cultures, forced disappearances), and her own spoken commentary, Figueroa Álvarez's lecture was a multilayered performance in its own right.

\section{Example 2: Scenography and the Public Space}

In her presentation "Sound and Safe" (thematic block 'Scenography and Sound,' moderated by Cat Fergusson), Natalie Harb voiced her interest in the 'sonic inequity' experienced by inhabitants of cities. Her ongoing project The Silent Room, a wooden structure, painted in pink or navy blue, that she temporarily mounted in Beirut $(2017,2018)$ and as a part of London Design Biennale (2018) questions the notion of 'shelter' and its meaning in the given geopolitical context. (Harb 2019) In Harb's vision, bridging 'spatial' and 'sonic' practices (Harb 2019), scenography deliberately intersects with social justice, reconfiguring the public space with its implied hierarchies with temporary spatial structures that isolate sonic pollution to offer an opportunity to practice what Hannah Arendt has referred to as 'vita contemplativa' as the philosophical act of thinking that requires solitude and withdrawal from the public realm, and is

\footnotetext{
${ }^{1}$ Stefany Duarte is an actress and director of Laboratorio de Experimentación Teatral in Mexico, who participated in the Mexican entry to the Performance Design Section. As Figueroa Álvarez clarified in an email, Duarte's performance was in fact coincidental. When Duarte had learned about Figueroa Álvarez's planned talk, she immediately approached her about possible collaboration; Figueroa Álvarez agreed. (Email with B. P. April 12, 2020).
} 
distinguished from 'vita activa' that unfolds in dialogue and interaction with the others in the public sphere (1998, 7-17). For Arendt, who developed her political theory in response to the twentieth-century European totalitarianisms, these two ways of living are equally important in maintaining plurality in politics as she is interested in "think[ing] what we're doing" $(1998,5)$. In similar ways, while disrupting the distinctions between the private and the public space, Harb's Silent Rooms, extraordinary in their bright colors, serve not only as a place for refuge but also as nests of potential political activity as they enable their guests to 'think what [they're] doing' in the midst of urban noise.

Arendt's insistence on the necessity to complement 'thinking' with 'action' to sustain a heterogeneous public sphere can be found in the work of scenographer and researcher Nevena Mrdjenovic. Similar to Harb, who conceptualizes her projects as research, Mrdjenovic claims to use scenography to 'think of, through, and with space.' (2019) In her talk (thematic block 'Scenography and Memory'), she presented her project TRAVELS, for which she visited and photographed 11 war-torn homes in the former Yugoslavia. Using her knowledge, skills, and sensibility of a scenographer, she investigated these spaces with their remaining objects as "abandoned mise-en-scenes" to get a better understanding of the people who used to inhabit them and the forms of violence that had taken place in them. Ultimately, this investigation has helped her to gain an alternative access to the trauma, one that goes beyond the official, often manipulated, historical narratives (Mrdjenovic 2019).

\section{Example 3: The Simplicity of a Performance Space}

Theatre in the Wild, one of the projects awarded at PQ 2019: Performance Space Exhibition, was a concept of a temporary structure for an art festival, organized in Ping Che, a rural village located at the Northeastern New Territories of Hong Kong in 2016. This was one of the projects that deployed scenography as a creative and non-violent way of responding to local concerns while opposing — or rather, intentionally not resonating — with extraneous cultural and ideological impositions. PQ 2019 coincided with the earliest phases of mass protests in Hong Kong against mainland Chinese control. While this project does not declare any political standpoint or engage in an open ideological conflict, its sensitive approach to local environments, its respectful acknowledgement of the quality and ways of life here and now, and its imaginative and unassuming interventions into public spaces are an important statement on the value of scenographic art and its power to transform the world around us.

The video presenting Theatre in the Wild sums up its objectives as "revealing history and stories of the abandoned space" in Ping Che while creating ecologically conscious design, based on local resources and inhabited by local artists. The festival consisted of a host of artistic initiatives, including music concerts, theatre, dance, installation works, artist-led workshops, 
guided walks, and a discussion forum. The temporary, flexible performance space of the festival was created by a translucent "ribbon of fabric attached to bamboo poles" whose shape "echoes the shape of mountain ridges."

The environmental concern is apparent but is not an ideological statement but rather a mode of operation. Similarly the low-cost practicalities of the initiative secure the project's sustainability. Very importantly, Theatre in the Wild is not dependent on media; its eco-friendliness extends to 'info pollution': the project does not produce virtual and other disembodied realities.

\section{Example 4: Multipurpose Performance Space}

Supported by Dorte Lena Eilers of Theater der Zeit publishers, the creative team comprising scenographer Sebastian Hannak and artistic director (Intendant) of Oper Halle Florian Lutz presented their award-winning project Raumbühne Heterotopia (Stage Space Heterotopia) that was realized at the Halle Opera House in 2016/2017. ${ }^{2}$ In Heterotopia Hannak created a performance space that comprised the Halle Theatre's stage, backstage and the entire auditorium of the 1886 building. Hannak's scenography served as the environment for several distinct productions - Wagner's opera Der fliegende Holländer, Sarah Nemtsov and Dirk Laucke's new opera Sacrifice, Ralf Rossa, Ivo Nitschke and R.S.'s ballet Groovin'Bodies, and Elfriede Jelinek's drama Wut.

In our view this scenographic concept is remarkable for a number of reasons (discussed below in more detail): (i) as a scenographic riposte to the heritage of theatre architecture; (ii) as an exploration of the social hierarchies of space; (iii) as a performance space for widely diverse genres and art forms; (iv) as a space that cultivates the communitas of Oper Halle's audiences and regular theatregoers; and (v) as an imaginative experiment in sustainability. As the presenters explained it in the brief of their talk, in Heterotopia:

The boundaries between audience, orchestra and performers blur in favour of an immersive spatial experience and empathic total theatre. It offers an experimental field for artistic attempts to completely rethink the genre of opera in its social and political dimensions.

(i): A scenographic riposte to the heritage of theatre architecture. The Halle Opera House is an 1886 traditional proscenium stage with a three-tier auditorium - a prime example of the imperial architectonic model of the theatre. Replicating and reifying the formulas of social stratification, the space may be suitable for nineteenth-century operas, but certainly less so for contemporary works. Heterotopia deconstructed the architectonic setup of the theatre beyond recognition. With

\footnotetext{
${ }^{2}$ The publishing house Theater der Zeit issued a volume dedicated to the project: Sebastian Hannak und Florian Lutz, eds. Raumbühne Heterotopia: neue Perspektiven in Musiktheater. Berlin: Theater der Zeit, 2018.
} 
a production of a Wagner opera at the heart of the season, the newly created stage space 'made strange' (in the Shklovskian sense) and imaginatively questioned the received values that the building's architecture embodies. In this sense, Hannak's Heterotopia became a site-specific scenography of sorts, approaching the traditional architectonic structure as a found space (cf. Pamela Howard's 2019 edition of What is Scenography? and her 'site-specific' treatment of the Opera House in Ljubljana, Howard 2019, 231-233 and 251-253).

(ii): An exploration of the social hierarchies of space. The resulting scenography was far from a democratic space. In a sophisticated dialogue with the hierarchies of the 1886 architecture, Heterotopia placed its audiences in different locations - with wildly different sightlines, access to the central action or the performers (such as the vicinity of the orchestra), or spatial relationships to one another. While some spectators were tucked away in splendidly isolated boxes, others were seated on the stage, one group provocatively segregated from the action by a fence with a barbed wire on top. By this conspicuous distribution of audiences into segregated groups, Hannak's Heterotopia materialised an awareness of social hierarchies, highlighting differences - not to codify or endorse them but to acknowledge them and invite a critical reflection and dialogue.

(iii): A performance space for widely diverse genres and art forms. This scenographic concept clearly could not operate with descriptive sets or symbols specific to a particular dramatic work since the performance space had to cater for four widely diverse productions, directed by three different artists. Rather than being a one-size-fits-all, Heterotopia was spatial canvas - an imaginative environment nuanced by structural details to accommodate the four different productions with all their changes and internal varieties. The aesthetic osmosis - the bleed between individual productions - had significant consequences for the theatre as a social institution too, and that on a number of levels:

(iv): A space that cultivates the communitas of Oper Halle's audiences and regular theatregoers. Heterotopia, even by its very name, was out of the ordinary. By transforming the well-known and much-frequented space of the Oper Halle building into an 'other' space, it gave it a festive atmosphere. In that way, Hannak and Lutz revisited the social function of theatre within the (German) concept of theatre as a public institution that materialises and cultivates the city's public. The Heterotopia season indeed brought 'something special' to its regular theatregoers, and understandably contributed to a heightened awareness of a communitas (to use Victor Turner's word). Additionally, seeing one production in the Heterotopia space must have necessarily intrigued audiences and encouraged them to come and see the other productions of the season. In that way, the scenographic concept fulfilled a function of publicity for the remainder of the season.

(v): An imaginative experiment in sustainability. While monumental in its concept, Heterotopia did address one of the burning issues of the present day (and also of PQ 2019): the sustainability and environmental responsibility of theatre makers. While creating one single stage space, which 
allowed for variants for the four individual productions, it economized on the overall resources that would have been wasted if four distinct scenographies designs were to be created for its productions - in addition to the labour needed for the daily fitting and dismantling of the sets: a reality in the German repertory system that avoids runs in a single fit-up. Heterotopia could well serve as an inspiration for other imaginative creations that take sustainability and environmental responsibility as their standard mode of operation - as well as models for achieving festivity that goes beyond the wastefulness of single use solutions.

\section{Conclusion}

The projects, propositions, and ideas presented at PQ Talks 2019 manifested themselves as practices deeply rooted in human relationships that spring from intellectual and creative generosity, sharing and exchanging ideas as 'gifts' as well as the willingness to be open to a possible misunderstanding or failure. This goes against the institutionally endorsed model of individual authorship that artists hold for their scenographic contributions to a performance and against the Western neoliberal emphasis on productivity and product.

Our curatorial approach of PQ Talks was based on the ethics of openness and care. Many of the other PQ programmes depend - explicitly or implicitly—on the political and material support of the sending countries or wealthy institutions and establishments. A number of the speakers of PQ Talks brought views that were alternative to the official exhibitions of PQ's main programme (Exhibition of Countries and Regions) or spoke about scenographic practice that would fall outside the official discourse, the self-presentations of national institutions, and even outside the establishment. We believe that the next steps for PQ Talks - and perhaps even for the Prague Quadrennial as a whole - is to negotiate these political aspects of scenography and performance design, towards a forum that is more inclusive in a number of dimensions:

- politically: to include majority voices as well as counter discourses;

- economically: to reduce the necessity of affluence to join PQ;

- artistically and institutionally: to offer more space to independent and freelance culture;

- epistemically: to overcome the barriers raised by research policies and the power play of academic institutions and universities, and to complement the Baconian dictum of "Knowledge is Power" by unyoking the two concepts, and enriching our epistemics by the knowledge of the powerless and disempowered.

PQ Talks crucially included creative work in the theatre and in performance events. However, the way scenography was inflected and practised as a creative art form was much broader. In the many approaches and projects from around the world, like the examples discussed above, a recognizable feature could be notionally identified: they give shape to - a space for a human individual to exist, act, live in and alertly respond to. These newly shaped 'ecologies' are creative formations. They may or may not be designed by the scenographers. They can also be 
found and given shape by a human gesture, and - crucially_offered as a gift of space to others to inhabit. We believe that this human gesture of space-giving - of creating a welcoming environment for other people to move into - sits at the very heart of what world scenography of 2019 is.

\section{Bibliography}

Arendt, Hannah. 1998 [1958]. The Human Condition. Chicago: University of Chicago Press. Figueroa Álvarez, Tamara. 2019. TRADITION/TRADUCTION: The Scenic designer as a translator of artistic language. Paper Presented at PQ Talks, June 6-16, in Prague, Czech Republic.

Harb, Natalie. 2019. Sound and Safe: On Urban shelters. Paper Presented at PQ Talks, June 6-16, in Prague, Czech Republic.

Mrdjenovic, Nevena. 2019. Forensic Scenography: Scenographic Strategies in Tracing Post-War Domestic Mise-en-Scène. Paper Presented at PQ Talks, June 6-16, in Prague, Czech Republic.

Příhodová, Barbora, Joslin McKinney, and Sodja Lotker. 2016. The Prague Quadrennial of Performance and Design Space 2015 [Editorial] Theatre and Performance Design 2, no 1-2: 7-9.

Santos, Boaventura de Sousa. 2014. Epistemologies of the South: Justice Against Epistemicide. Abindgon and New York: Routledge. 